\title{
Construyendo un nuevo periodismo. Diez años de logros y retos en la prensa digital
}

\author{
Ramón Salaverría*
}

\section{Resumo}

Hoy nadie cuestiona ya que internet sea una plataforma prioritaria para el periodismo. Y este es sólo uno de los muchos los logros alcanzados por los cibermedios durante sus diez primeros años de vida. Ahora bien, sigue habiendo importantes incógnitas por despejar. Señalaremos cuatro de esos retos pendientes, que estimamos de especial relevancia para el desarrollo futuro del ciberperiodismo: 1) la exploración de nuevos lenguajes periodísticos para aprovechar las posibilidades comunicativas de la Red, 2) la consolidación de nuevos estándares profesionales para el ejercicio del ciberperiodismo, 3) la instauración de modelos de negocio sostenibles en internet y 4) la formación de los periodistas en el uso de las nuevas tecnologías.

Palabras-chave: ciberperiodismo, nuevas tecnologías, retos de los cibermedios, obstáculos de los media

El 19 de enero de 1994 aparecía en la Web el primer ejemplar digital del Palo Alto Weekly, una veterana revista editada en la ciudad homónima de la bahía de San Francisco, en Estados Unidos. Esa publicación, cuyo modesto primer número aún puede leerse en internet (Palo Alto Online, 2004), no habría pasado a la historia si no fuera por un pequeño detalle: se trata del primer medio escrito publicado de manera regular en la Web (Carlson, 2003: 49-50).

Por supuesto, antes de que apareciera en la Red esta revista californiana, otros muchos medios impresos habían experimentado ya desde finales de los años 1980 con diversas iniciativas de prensa electrónica a través de servicios digitales anteriores a la Web. Dentro y fuera de Estados Unidos, un buen número de publicaciones se venían

* Professor de jornalismo na Universidade de Navarra e autor do blog sobre jornalismo digital: http://e-periodistas. blogspot.com/ (rsalaver@unav.es). 
editando ya mediante videotex o, más habitualmente, mediante servicios privados de conexión como America Online, Compuserve o Prodigy. Sin embargo, la historia de la prensa en la Web propiamente dicha comenzó aquel 19 de enero de 1994.

Hoy día, cuando ya se ha cumplido más de una década de aquel pistoletazo de salida, la cifra de cibermedios que pueblan la Red se ha multiplicado exponencialmente. No existen registros exhaustivos de cibermedios a escala mundial, pero sin lugar a dudas la cifra de medios en internet alcanza varias decenas de miles y quizá, incluso, centenares de miles. Yahoo!, por ejemplo, cataloga más de 9.000 ediciones digitales de diarios impresos en todo el mundo (Yahoo!, 2005). Sin embargo, éste parece ser un registro incompleto. Sólo en España, considerando apenas a las ediciones digitales de los periódicos y revistas así como a las radios y televisiones en internet, a finales de 2004 un equipo investigador en el que participo ha llegado a censar más de 1.400 de publicaciones digitales (Pereira et al., 2004). Y recordemos que en el mundo hay más de 200 países.

Sea cual sea la cifra exacta de cibermedios en el mundo, lo importante es que su multiplicación exponencial ha hecho que internet deje de ser un entorno marginal, sólo apto para especialistas, y se haya convertido en un medio de comunicación primordial. Los datos de audiencia así lo avalan. Por ejemplo, a comienzos de 2005, uno de cada tres españoles era usuario habitual de la Red (véase Tabla 1). Portugal exhibía unas cifras notablemente mejores: por esas mismas fechas, eran usuarios habituales de internet más de 6 de los casi 10,6 millones de portugueses (ClickZ, 2005). En otros países europeos, como por ejemplo en el Reino Unido, Holanda y sobre todo en los países escandinavos, el porcentaje de usuarios de internet alcanzaba ya cifras superiores al $70 \%$ de la población (ClickZ, 2005).

A esta popularización mundial de la Red han contribuido en gran medida los medios de comunicación. La gente se ha acostumbrado a realizar en internet una de sus actividades habituales: informarse (Cerezo \& Zafra, 2003). Según la European Interactive Advertising Association (EIAA), en noviembre de 2004 internet se había convertido ya en el primer medio escrito en Europa (EIAA, 2004). Los europeos dedicaban el 20\% de su tiempo de consumo de medios a leer informaciones en la Red; casi el doble de

\section{Tabla 1}

\begin{tabular}{|l|r|r|r|r|r|r|r|r|r|}
\hline \multicolumn{10}{|c|}{ \% DE USUARIOS DE INTERNET EN ESPANA RESPECTO DE OTROS MEDIOS } \\
\hline & 1996 & 1997 & 1998 & 1999 & 2000 & 2001 & 2002 & 2003 & 2004 \\
\hline Diarios & 38,2 & 37,7 & 36,9 & 35,2 & 36,3 & 35,9 & 35,8 & 37,4 & 41,0 \\
\hline Radio & 56,6 & 55,0 & 53,5 & 53,0 & 52,9 & 52,4 & 52,5 & 54,7 & 57,7 \\
\hline TV & 91,3 & 90,7 & 89,4 & 89,4 & 89,2 & 89,2 & 89,3 & 89,9 & 90,2 \\
\hline Internet & 1,0 & 2,7 & 4,6 & 7,0 & 12,6 & 20,4 & 21,1 & 22,5 & 30,6 \\
\hline
\end{tabular}

Fuente: Estudio General de Medios (EGM), 1996-2004 
tiempo que quienes leían periódicos $(11 \%)$ y muy por delante de los lectores de revistas $(8 \%)$. A medio plazo, se anunciaba asimismo un profundo impacto en los medios audiovisuales. Según el estudio "Entertainment and Media Outlook: 2004-2008", de la consultora PricewaterhouseCoopers, en los siguientes cuatro años el volumen de negocio de internet alcanzaría al de la televisión (PwC, 2004).

No hay dudas, en fin, de que los cibermedios salen reforzados de su primera década de vida. Hoy nadie cuestiona ya que internet sea una plataforma prioritaria para el periodismo. Y este es sólo uno de los muchos los logros alcanzados por los cibermedios durante sus diez primeros años de vida.

Ahora bien, sigue habiendo importantes incógnitas por despejar. Señalaremos cuatro de esos retos pendientes, que estimamos de especial relevancia para el desarrollo futuro del ciberperiodismo: 1) la exploración de nuevos lenguajes periodísticos para aprovechar las posibilidades comunicativas de la Red, 2) la consolidación de nuevos estándares profesionales para el ejercicio del ciberperiodismo, 3) la instauración de modelos de negocio sostenibles en internet y 4) la formación de los periodistas en el uso de las nuevas tecnologías.

\section{Reto 1: desarrollar nuevos lenguajes}

El primer reto es de carácter lingüístico. Las publicaciones digitales han importado de los medios anteriores - en particular, de la prensa - sus formatos y géneros. De hecho, en sus orígenes los cibermedios no eran más que simples reproducciones en la Red de los contenidos previamente elaborados para el papel. Por lo tanto, el primer lenguaje de los cibermedios no fue otro que el de la prensa impresa.

Sin embargo, a medida que los cibermedios comenzaban a elaborar y publicar contenidos propios, y de que los contenidos audiovisuales multiplicaban su protagonismo en la Red, descubrieron que cabía explorar nuevas posibilidades expresivas. Esas posibilidades lingüísticas del ciberespacio se resumen en tres rasgos: hipertextualidad, multimedialidad e interactividad. El reto lingüístico de los cibermedios consiste en desarrollar unos lenguajes que aprovechen esas tres cualidades.

A pesar de que muchas publicaciones digitales recurren todavía al modelo primitivo de reproducir contenidos procedentes del papel, proliferan los cibermedios que no sólo elaboran contenidos propios, sino que lo hacen con formatos nuevos. El saldo de esta evolución es todavía modesto, pero permite identificar ya endemismos periodísticos exclusivos de internet. Géneros periodísticos como la infografía interactiva, los reportajes multimedia o múltiples variantes de textos dialógicos - entrevistas, charlas, foros, encuestas... - abanderan la renovación de un lenguaje periodístico que vive un período de notable fecundidad (Díaz Noci y Salaverría, 2003: 15-43).

Estos cambios, a pesar de todo, han sido hasta la fecha más modestos de lo que cabría esperar. En general, las empresas de comunicación han mostrado poco interés por experimentar con formas novedosas de contar la información y se han mostrado reacios a aprovechar las posibilidades comunicativas del ciberespacio. Por ejemplo, la 
posibilidad de establecer un diálogo directo con los lectores, ampliamente utilizada desde hace tiempo por los weblogs, resulta todavía excepcional en los cibermedios institucionales, donde el modelo de comunicación unidireccional sigue siendo hegemónico. Además de desaprovechar las posibilidades comunicativas de la Red, se ha detectado asimismo poco interés por crear equipos de redacción sólidos y por formar a los periodistas en las nuevas destrezas profesionales que demanda internet. Hoy día, los periodistas que trabajan en cibermedios siguen siendo poco valorados y sus condiciones laborales son con frecuencia peores que las de sus colegas en medios tradicionales. Cuando echaron a andar los primeros cibermedios a mediados de los años 1990, se esperaba una exploración más fecunda del lenguaje periodístico en la Red y se vaticinaba asimismo una consolidación profesional de los periodistas mucho más rápida. Sin embargo, diez años después, la realidad no alcanza las expectativas que se generaron entonces (Paul, 2005).

\section{Reto 2: consolidar el periodismo multiplataforma}

$\mathrm{El}$ auge de los cibermedios ha acentuado un segundo reto para las empresas de comunicación: la necesidad de coordinar las estrategias editoriales y de marketing de sus distintos medios impresos, audiovisuales e interactivos. Se trata del advenimiento de lo que se ha dado en llamar el periodismo multimedia o multiplataforma (Salaverría, 2005a: 37-40).

Este cambio se ha producido de manera paulatina en las últimas décadas. Hasta aproximadamente 1990, en los países occidentales eran minoría los medios de comunicación que formaban parte de un grupo de comunicación multimedia; lo habitual, por el contrario, era que los periódicos, emisoras de radio y canales de televisión fueran propiedad de una empresa autónoma, sin intereses en otros ámbitos de la comunicación (véase Figura 1).

Figura 1

1980-1990: autonomía de medios impresos y audiovisuales

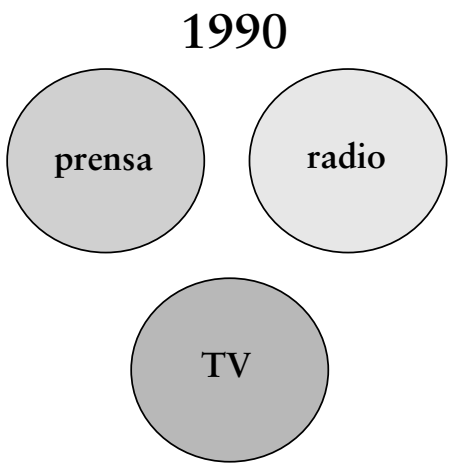


Figura 2

1990- 2000: convergencia empresarial y aparición de un cuarto medio, internet

\section{0}

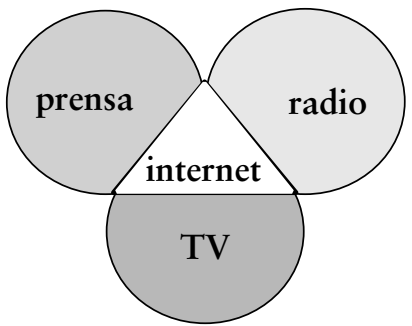

Sin embargo, durante la década de 1990, a semejanza de lo que ocurría en otros muchos sectores económicos, en el ámbito de los medios se produjo un rápido proceso de concentración empresarial; muchas empresas pequeñas fueron absorbidas por grandes multinacionales de la comunicación. Esta concentración empresarial llevó aparejada, además, la diversificación mediática. Nacieron así los grupos de comunicación multimedia de nuestros días, con intereses en prensa escrita, radio y televisión. $\mathrm{Y}$, en mitad de ese proceso, ocurrió algo que ninguno de esos grupos esperaba. Hacia mediados de la década, surgió una cuarta plataforma para los medios: internet (véase Figura 2). Así, de manera bastante tímida y recelosa al principio, y con mayor decisión más adelante, los grupos de comunicación comenzaron a presentar sus publicaciones en el ciberespacio. No en vano, se trataba de una plataforma con especial atractivo para el público joven, un público cada vez más alejado de los medios tradicionales y en particular de la prensa impresa, y donde se adivinaban abundantes posibilidades de negocio por explorar.

En la primera década del siglo XXI estamos asistiendo a un nuevo paso en este proceso. Múltiples indicadores apuntan a que, al menos en los países occidentales, los periódicos impresos se encaminan hacia un futuro cada vez más complicado: sus cifras de difusión se mantienen en constante declive, no consiguen atraer al público joven, se enfrentan a la creciente competencia de los diarios gratuitos y encuentran una competencia comercial cada vez mayor en el mercado de la publicidad y los clasificados. Estos problemas han llevado a algunos a augurar incluso la desaparición de la prensa impresa para el año 2020 (Martínez Albertos, 1997). Probablemente, la situación no alcance niveles tan dramáticos, pero resulta cada vez más evidente que el futuro de la prensa impresa se dirige a ceder su actual protagonismo informativo a otros medios, en particular a internet y a la televisión - sobre todo, una vez que se consolide la televisión digital (véase Figura 3).

Por otra parte, otra de las tendencias cada vez más claras en este ámbito es la coordinación de estrategias editoriales y comerciales entre los medios pertenecientes 
Figura 3

Futuro: consolidación de la convergencia multimedia y redistribución del protagonismo
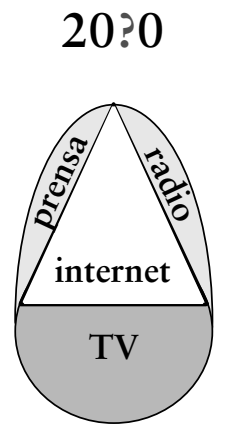

a un grupo multimedia. Hoy día, los medios se gobiernan cada vez menos de manera autónoma. En sus decisiones editoriales y mercadotécnicas, atienden a estrategias de grupo planificadas desde instancias superiores. Esta coordinación de estrategias se hace especialmente visible en internet, una plataforma capaz de integrar los contenidos provenientes de los medios impresos y audiovisuales. Así, algunos cibermedios se han convertido en gestores o repositorios de los contenidos elaborados por sus hermanos del papel o de las ondas.

El advenimiento del periodismo multiplataforma ha obligado a renovar los mecanismos de producción en los medios. Cada vez más, se tiende a implantar aplicaciones tecnológicas - los llamados sistemas de gestión de contenidos, basados en tecnología $\mathrm{XML}$ - que posibilitan la circulación ágil de contenidos textuales y audiovisuales a través de los distintos medios de un grupo. Esta reforma tecnológica conlleva una transformación profesional de los periodistas. Lo textual y lo audiovisual, ámbitos antaño claramente separados, tienden a estar cada vez más solapados y se adivina un futuro cercano en el que los periodistas habrán de combinar en su trabajo la destreza redaccional con el conocimiento de las claves de la narrativa audiovisual.

\section{Reto 3: afianzar los modelos de negocio en la Red}

Una de las mayores incógnitas que pesa sobre los cibermedios sigue siendo la de su rentabilidad. Diez años después de su aparición, la mayoría de los cibermedios continúa en números rojos, algo que, como es evidente, lastra su desarrollo y retrae la inversión.

Los cibermedios han experimentado durante los últimos años diversas fórmulas para ser rentables. Al principio, adoptaron un modelo gratuito que confiaba su suerte a la publicidad. Cuando ésta, a raíz de la crisis puntocom, desapareció de la Red a principios de 2000, los cibermedios pasaron a experimentar con modelos de cobro parcial o total por contenidos. 
Esto ha hecho que en 2005, convivan modelos de negocio muy dispares en la Web. Hay publicaciones digitales que van desde la gratuidad hasta el cobro absoluto, pasando por una gran variedad de modelos mixtos. En realidad, la gran mayoría de los cibermedios recurre al modelo gratuito o bien, cada vez más, a un modelo mixto en el que se mantiene una importante oferta libre si bien se cobra sólo por algunos servicios especiales (consulta de archivo, edición facsímil en PDF, acceso a informes especiales, etc.). Sólo algunos pocos medios siguen apegados al estricto modelo de cobro total por contenidos. De hecho, esta parece ser la tónica en todos los países. En Estados Unidos, por ejemplo, a comienzos de 2005 sólo 36 de los 1.400 diarios contaban con una edición digital íntegramente de pago.

En los próximos años, la proliferación de los periódicos gratuitos y la multiplicación de oferta informativa en la Web - donde sobresalen cada vez más los weblogs - auguran dificultades para aquellos cibermedios que mantienen un modelo estrictamente de pago. La tendencia general de la prensa digital apunta hacia la adopción de modelos mixtos, sobre todo ahora que la publicidad en internet recupera vigor.

\section{Reto 4: formar para el nuevo periodismo}

El cuarto gran reto es el de la formación. Los jóvenes periodistas y, sobre todo, aquellos más veteranos que han vivido la revolución digital en las redacciones reclaman nuevas destrezas. Para ejercer el periodismo del siglo XXI - no sólo en publicaciones de internet, sino en cualquier medio - es imprescindible dominar los recursos y redes digitales.

Estas necesidades de reciclaje alcanzan a las labores informativas de investigación, producción y difusión. En primer lugar, sin abdicar de los procedimientos clásicos, la investigación periodística moderna exige conocer técnicas documentales para el manejo avanzado de buscadores y bases de datos. El aprendizaje de esas técnicas debe ir acompañado, además, del desarrollo de un conocimiento crítico para distinguir en internet las fuentes dignas de crédito de las que carecen de toda credibilidad. En segundo lugar, por lo que se refiere a las tareas de producción informativa, la composición de nuevos contenidos periodísticos reclama, como ya hemos dicho, dotes comunicativas donde la hipertextualidad, multimedialidad e interactividad comiencen a ser incorporadas de manera cotidiana en el quehacer periodístico. Por último, los periodistas deben aprender las peculiaridades de una nueva plataforma de difusión como la Red y, en particular, deben responder a las demandas de un nuevo público, mucho más participativo y exigente.

\section{Mirando al futuro}

Los diez primeros años de la prensa digital dejan demasiados retos pendientes como para afirmar que los cibermedios hayan llegado ya a su madurez (Salaverría, 2005b). Es mucho lo avanzado en una década, pero todavía queda largo camino por recorrer. 
En este sentido, se adivinan algunos factores que, en nuestra opinión, cobrarán especial protagonismo en el desarrollo de los medios en los próximos años.

La primera cuestión es la emergencia de un nuevo modelo de periodismo en el que el diálogo con el público y la interactividad se configurarán cada vez más como elementos fundamentales de la actividad periodística. Este tipo de periodismo, bautizado ya como periodismo participativo (Gillmor, 2004) o periodismo 3.0 (Varela, 2005), plantea una socialización de la información, donde el público deja de ser un mero receptor de la información para convertirse en un interlocutor activo de los medios.

El segundo factor es de tipo económico. Todo indica que la evolución de internet va a convertirse en un factor clave no sólo, como es obvio, en la gestión de los cibermedios, sino también en la propia supervivencia empresarial de los medios tradicionales. Áreas no demasiado alejadas del periodismo como la producción musical y cinematográfica, en las que de hecho muchas empresas de comunicación tienen intereses, están viendo cómo sus modelos de negocio tradicionales resultan seriamente afectados a causa de la Red. La prensa impresa también ha experimentado un efecto similar; la competencia creciente de las publicaciones de internet ha sumido en muchos casos en el desconcierto a los responsables de los periódicos impresos. Este tipo de problemas, lejos de remitir, se multiplicará en el futuro.

En particular, las innovaciones tecnológicas más recientes en el ámbito de internet, caracterizadas por la portabilidad de los aparatos de conexión a la Red y por la mejora en los dispositivos de transmisión, archivo y visionado de contenidos audiovisuales, dibujan un futuro donde la televisión clásica experimentará a buen seguro una competencia que hoy no tiene. En un entorno donde el público podrá consumir a través de la Red contenidos audiovisuales de todo tipo, sin necesidad de someterse al visionado de la publicidad, en cualquier momento y desde cualquier lugar, las televisiones generalistas se enfrentarán a un entorno particularmente complicado. Internet se convertirá así en un factor clave en el proceso de fragmentación de las audiencias televisivas.

Todos estos factores, y probablemente otros que todavía ni siquiera presentimos, seguirán reconfigurando en los próximos años el mercado de los medios de comunicación y la propia profesión periodística. Pero no hay razones para la alarma; al fin y al cabo, en todo este proceso hay poco de revolucionario. Desde sus orígenes, la profesión periodística se ha visto acompañada siempre por una constante: la necesidad de acomodarse a los cambios. El futuro, más que nunca, exigirá seguir por ese camino.

\section{Bibliografía}

Carlson, D. (2003) 'The history of online journalism', 31-55 in Kawamoto, K. (ed.) (2003) Digital Journalism. Emerging Media and Changing Horizons of Journalism, Lanham: Rowman \& Littlefield Publishers.

Cerezo, J. M. \& Zafra, J.M. (2003) El Impacto de Internet en la Prensa, Madrid: Fundación Auna.

ClickZ (2005) 'Population explosion!', 7 de Julho. Disponível em: http://www.clickz.com/stats/sectors/geographics/article.php/5911_151151 
Díaz Noci, J. \& R. Salaverría (2003) Manual de Redacción Ciberperiodística, Barcelona: Ariel.

EIAA (2005) 'Consumers devote $20 \%$ of their media activity to the Internet', 9 de Novembro. Disponível em: http://www.eiaa.net/press-information/shwPress-information-releases.asp?id=39\&lang=1

Gillmor, D. (2004) We the Media. Grassroots of journalism by the people, for the people, Sebastopol, CA: O’Reilly Media Inc.

Martínez Albertos, J.L. (1997) El Ocaso del Periodismo, Barcelona: CIMS.

Palo Alto Online (2004) 'Palo Alto Online helps celebrate 10 years of online publishing'. Disponível em: http://www.paloaltoonline.com/news_features/online10/index.shtml

Paul, N. (2005) 'New News' retrospective: Is online news reaching its potential?', Online Journalism Review, 24 de Março. Disponível em: http://www.ojr.org/ojr/stories/050324paul/

PwC (2005) 'Consumers devote $20 \%$ of their media activity to the Internet', 9 de Novembro. Disponível em: http://www.narm.com/2004Convention/Pricewaterhouse.ppt

Pereira, J.; Gago, M.; López, X.; Díaz Noci, J.; Meso, K.; Salaverría, R.; Cabrera, M.A. \& M.B. Palomo (2004) 'El impacto de Internet en los medios de comunicación en España. Aproximación metodológica y primeros resultados'. Comunicação apresentada no II Congresso Ibérico de Comunicación, 23-24 de Abril, Covilhã, Portugal. Disponível em CD-ROM.

Salaverría, R. (2005a) Redacción Periodística en Internet, Pamplona: Eunsa.

Salaverría, R. (2005b) 'An immature medium: Strengths and weaknesses of online newspapers on September 11', Gazette: The International Journal for Communication Studies, vol. 67, n. ${ }^{\circ}$ 1, Fevereiro: 69-86.

Varela, J. (2005) 'Periodismo 3.0, la socialización de la información', Periodistas 21. Disponível em: http:// periodistas21.eapuntes.com

Yahoo! (2005) 'Yahoo! News Directory'. Disponível em: http://dir.yahoo.com/News_and_Media/ Newspapers/ 